\title{
TWO CASES OF OESOPHAGEAL STRICTURE IN CHILDHOOD REQUIRING RESECTION
}

\author{
BY \\ R. H. FRANKLIN and I. D. HENDERSON \\ From the Department of Surgery, Postgraduate Medical School of London
}

(RECEIVED FOR PUBLICATION OCTOBER 18, 1954)

Reflux oesophagitis appears to affect principally two great groups of patients, infants on the one hand and patients of late middle age on the other. The intervening years seem to be comparatively free from the condition and it is relatively uncommon for symptoms to occur for the first time in late childhood or early adult life. An exception to this generalization is the patient who develops oesophagitis in association with excessive vomiting of pregnancy. Most of the affected infants recover from their early oesophagitis either spontaneously or as the result of treatment, a few die, and in the remainder symptoms of oesophagitis persist.

One of the patients described below suffered from persistent symptoms starting in infancy and in the other the condition appears to have shown itself for the first time at the age of 13 years. In both patients resection was carried out and neither child has had any further symptoms.

\section{Case Reports}

Case 1. K.H., a girl aged 14 years, was referred from the Hammersmith Chest Clinic on August 10, 1951, with the complaint of recurrent attacks of 'vomiting' after meals.

She had been a normal healthy baby, breast fed till 1 year old. Subsequently there had not been any illness of note until September, 1950, when the present complaint began. The 'vomiting' occurred immediately after taking food and was associated with a feeling of sticking in the midsternal region. Pain was absent. The remittent attacks were precipitated by solids and were associated on some occasions with difficulty in swallowing liquids.

In the two months before consultation her symptoms had increased in severity. The patient's weight was $86 \mathrm{lb}$. (39 kg.). Physical signs of note were lacking. A barium swallow showed an oesophageal stricture at the level of the eighth thoracic vertebra and an associated hiatus hernia (Fig. 1).

The child was admitted for treatment. A diet of fortified milk was given together with olive oil and alka- line powders. In bed, an upright posture was maintained day and night. Twice daily autodilatation was carried out with gum-elastic bougies.

The symptoms improved steadily and by August 27, 1951, solids could be swallowed without regurgitation. She was discharged to attend as an out-patient, while maintaining the above régime, with the substitution of a normal diet for the fortified milk.

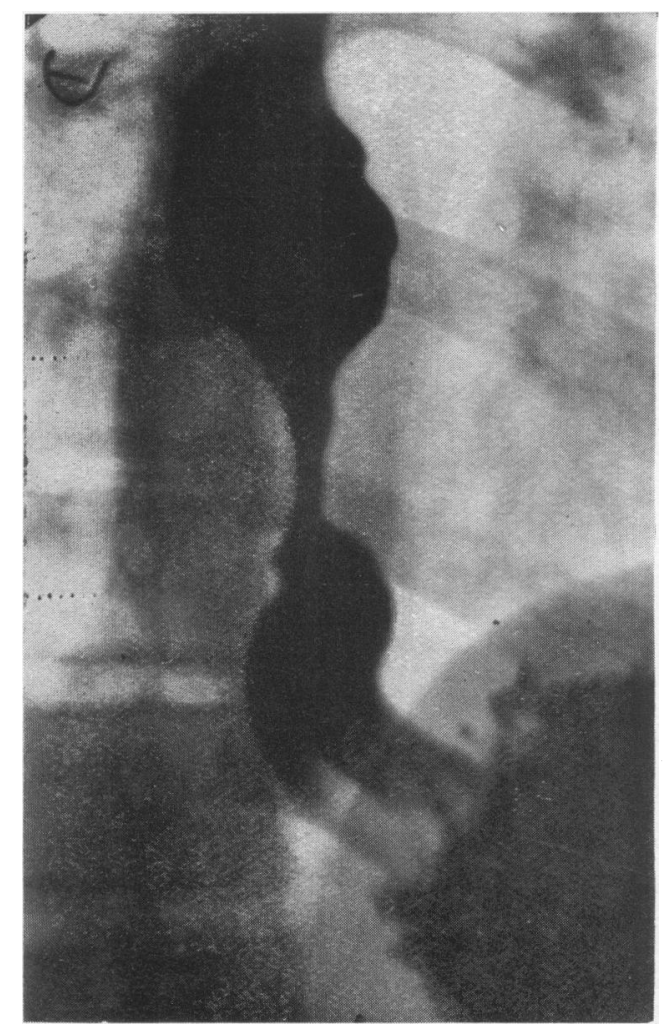

FIG. 1.-Radiograph showing oesophageal stricture and hiatus hernia. 


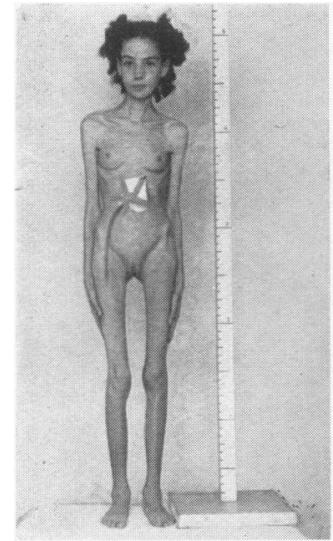

FIG. 2.-K.H. before resection of the stricture.

Unfortunately the patient defaulted and treatment was erratic. By February 26, 1952, severe symptoms had recurred, bougies could not be passed, and her weight had fallen to $73 \mathrm{lb}$. $(33 \cdot 1 \mathrm{~kg}$.). She was readmitted and the original régime was re-instituted with a slow but steady improvement. On discharge on May 2, 1952, solids could be swallowed with ease and her weight had increased to $100 \mathrm{lb}$. $(45 \cdot 4 \mathrm{~kg}$.).

After her discharge, however, she again relapsed and on readmission on September 20,1952, dysphagia had been severe for four weeks. The patient's weight had fallen to $55 \mathrm{lb}$. $(24.9 \mathrm{~kg}$.). A follicular rash was present but was limited to the abdomen and legs. The blood urea level was $206 \mathrm{mg}$. \% and haemoglobin $21.6 \mathrm{~g}$. $(147 \%)$.

Through a Ryle's tube an intragastric milk drip was started and simultaneously fluid was given per rectum. By the tenth day a positive fluid balance was being maintained, her weight had increased to $58 \mathrm{lb}$. $(26 \cdot 4 \mathrm{~kg}$.) and the rash was fading. The blood urea had fallen to $48 \mathrm{mg} . \%$. The Ryle's tube was removed and bouginage restarted. Unfortunately, following a period of continued improvement, a severe relapse recurred, her weight fell rapidly, and it proved impossible to re-insert the Ryle's tube.

On October 14, 1952, an inkwell type of gastrostomy was performed (Fig. 2). A month later, her weight was $67 \mathrm{lb}$. $(30 \cdot 4 \mathrm{~kg}$.). It was still impossible to pass a bougie. Because of this and because out-patient treatment had proved unsatisfactory, resection was advised.

At operation (R.H.F.) on November 18, the chest was opened through an incision in the eighth intercostal space on the left side. The left pulmonary ligament was divided and a hiatal hernia was at once apparent. Halfway between the arch of the aorta and the diaphragm the oesophagus was thickened and enlarged for a distance of $1 \frac{1}{2}$ in. There was associated peri-oesophagitis. The resulting mass felt stony hard and the impression on palpation was that the condition was indistinguishable from a carcinoma, although in view of the circumstances it was thought that the correct diagnosis was a chronic ulcer. The incision was prolonged inwards to divide

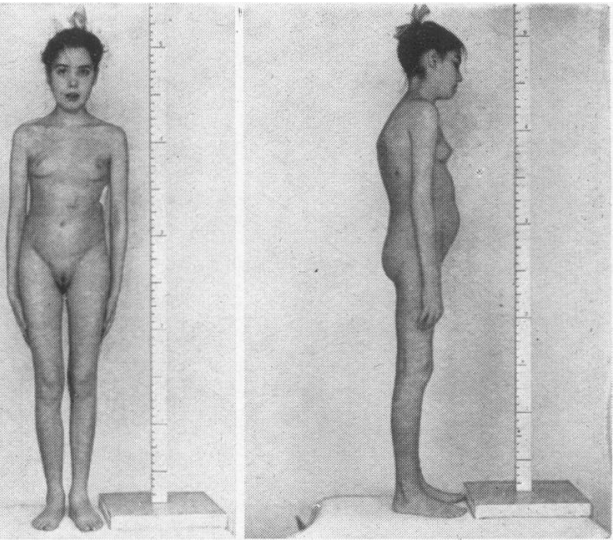

FIG. 3.-K.H. three months later after resection of the stricture.

the costal cartilage and the diaphragm was opened. The spleen was excised and the stomach mobilized by dividing the gastrocolic omentum and the left gastric artery and vein. Another intercostal incision was made through the fourth space and the oesophagus was freed to within $\frac{3}{4}$ in. of the arch of the aorta. The stomach was divided obliquely so as to remove most of the lesser curvature. The distal cut end of the stomach was closed with a double row of sutures and the rest of the stomach and the lower part of the oesophagus were removed. A separate incision was made in the closed distal part of the stomach and this was anastomosed to the cut end of the oesophagus just below the arch of the aorta. The diaphragm was approximated around the stomach and the chest closed around a large intercostal drain. The right pleura was widely opened during the resection because of pleural adhesions and an intercostal drain was introduced on the right side at the end of the operation. Both drains were led into waterseal bottles.

The girl made a very satisfactory recovery and was

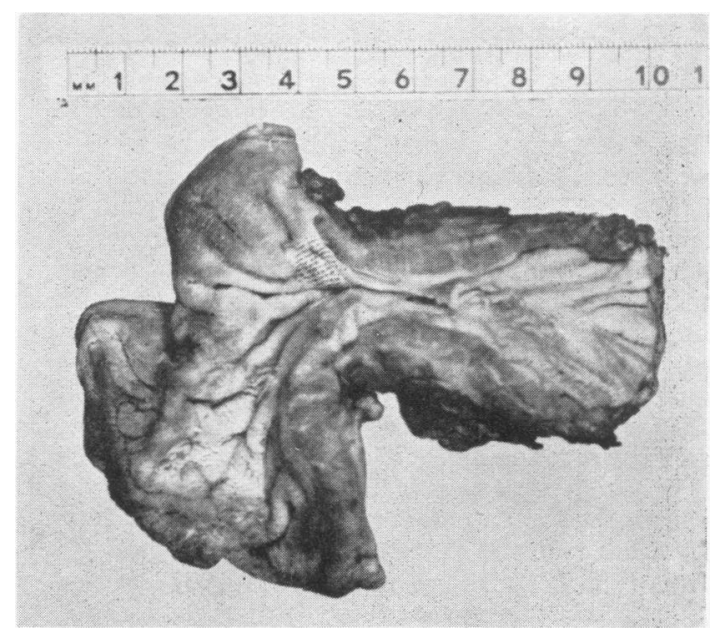

Fig. 4.-Part of the oesophagus resected showing the stricture. 


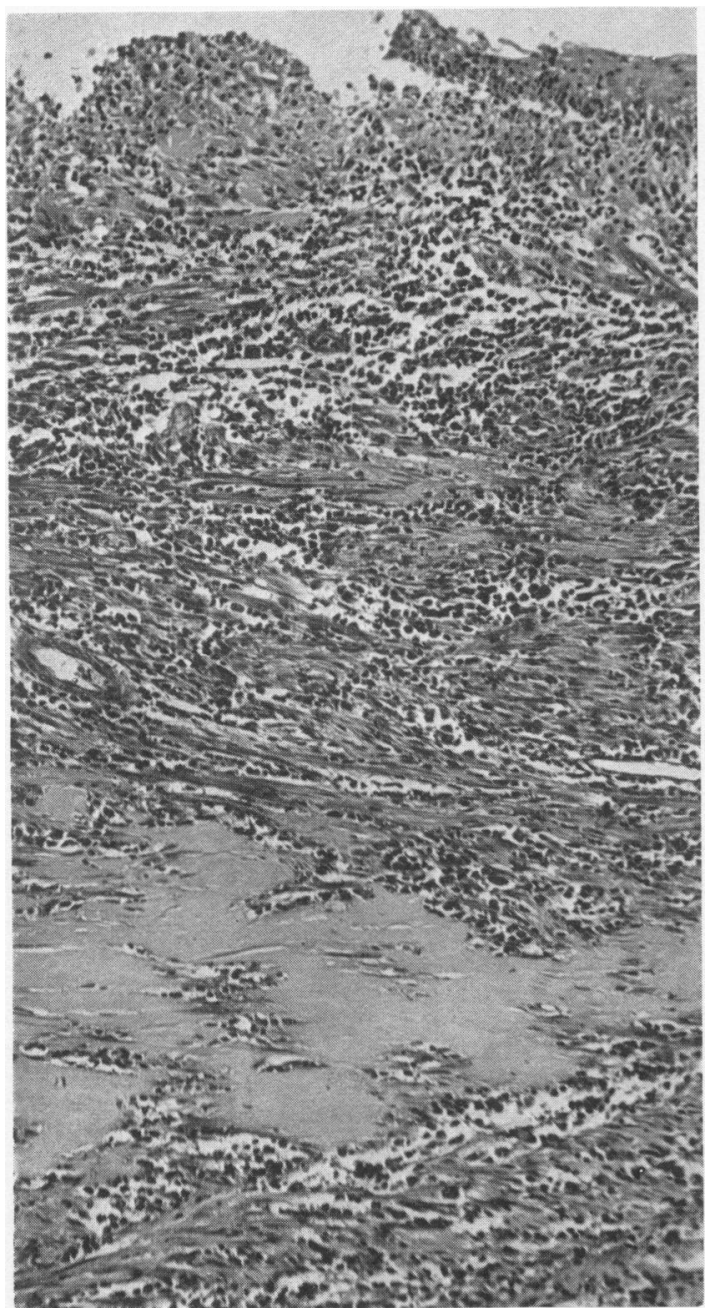

FIG. 5-Histological appearance of the stricture. Areas of osteoid tissue can be seen in the middle of the scar and the oesophageal mucosa shows ulceration.

discharged on January 15, 1953, her weight then being $101 \mathrm{lb}$. (45.8 kg.), and her clinical condition excellent (Fig. 3). She continued on an oesophagitis régime with alkalis and olive oil.

When last - seen on May 18, 1954, her weight was $110 \frac{1}{2} \mathrm{lb}$. $(50 \cdot 1 \mathrm{~kg}$.). For the previous five months she had not taken any medicine and had eaten a normal diet without any trouble.

The specimen (Fig. 4) showed that the stricture was caused by an excess of fibrous tissue involving all coats. In the midst of the scar tissue were areas of osteoid change (Fig. 5). In the oesophageal mucosa was a small ulcer with evidence suggestive of healing.

Case 2. C.T., a girl of 9, was referred for treatment by Mr. Alan Small.

After an uneventful first year of life, she started to have attacks of 'vomiting' with meals. Each attack lasted three or four days and recurred every two to four weeks. There were neither associated symptoms nor physical signs. A diagnosis of mental retardation was made and maintained until the summer of 1952. By then only liquids could be swallowed and her weight was falling rapidly. She was referred to $\mathrm{Mr}$. Small, who made a diagnosis of oesophageal stricture and hiatus hernia.

On admission on September 5, 1952, her weight was $53 \frac{1}{2} \mathrm{lb}$. $(24 \cdot 3 \mathrm{~kg}$.). The presenting symptom was effortless regurgitation on eating solids. A barium swallow confirmed the presence of a hiatus hernia with an oesophageal stricture at the level of the eighth thoracic vertebra (Fig. 6).

A régime similar to that described in Case 1 was started. On September 13, 1952, her weight was $62 \mathrm{lb}$. $(28 \cdot 1 \mathrm{~kg}$.). Three days later oesophagoscopy showed a marked gastric reflux, but no inflammatory changes or obvious stricture. The previous treatment was continued but attempts were made to convert the liquid diet to a solid one. By October 28, 1952, it had proved impossible on several occasions to institute this change without the recurrence of vomiting. Having regard to the patient's age and symptoms together with the oesophagoscopic findings, it was decided to try the effect of a repair of the hernia combined with a Heller-type operation on the spasmodic stricture.

At operation (R.H.F.) on October 28, the chest was

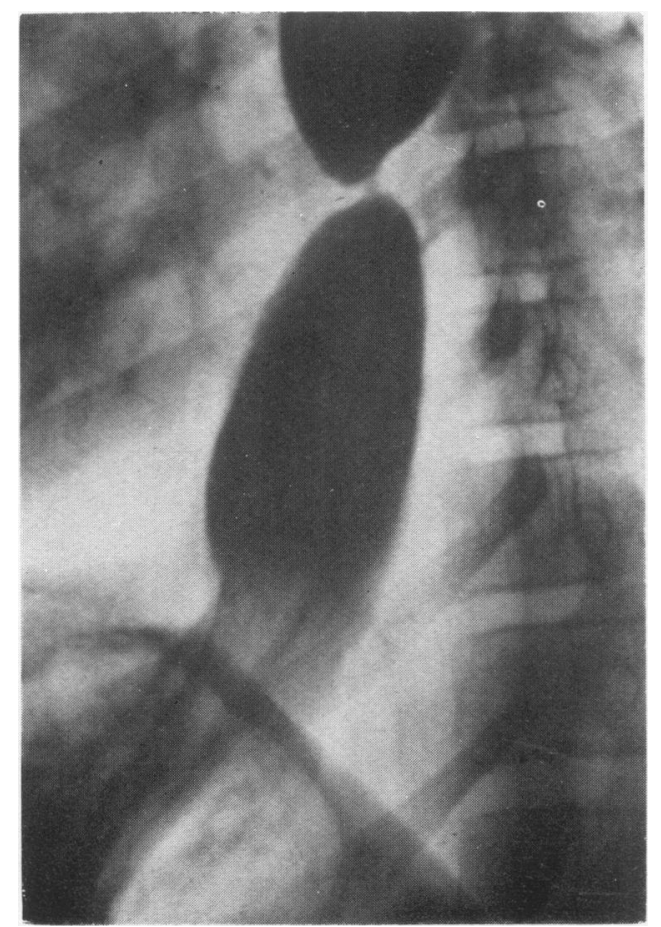

FIG. 6.-Radiograph showing stricture of the oesophagus with hiatus hernia. 
opened through an intercostal incision through the eighth left interspace. A hiatal hernia was present and the pleura overlying the oesophagus seemed to be very much thicker than normal and contained more blood vessels than usual. The left pulmonary ligament was divided to expose the lower part of the oesophagus and it was then seen that there was a stricture, $\frac{1}{2}$ in. in length, $2 \frac{1}{2}$ in. above the level of the diaphragm. At the level of the stricture the pleural adhesions appeared to be particularly thick and the oesophagus itself was thicker. An incision was made in the diaphragm away from the crus and the presence of the hernia confirmed. There appeared to be about 1 in. of stomach in the thorax, but it was difficult to determine the exact junction of the oesophagus and stomach. The muscles over the stricture were divided longitudinally and the epithelium was inspected. It appeared to be scarred. The lower oesophagus and cardiac end of the stomach were mobilized and the stomach was replaced below the diaphragm and kept in position with interrupted thread sutures passing through the phrenico-oesophageal ligaments and the crus of the diaphragm. The diaphragm was closed and an intercostal waterseal drain introduced and the thoracic wound closed.

The child made a good recovery from the operation but the difficulty in swallowing persisted and it had to be recognized that the operation had been a failure. It was, therefore, decided to carry out a radical excision of the affected part of the oesophagus.

At operation (R.H.F.) on December 2, the chest was re-opened through the same incision. The diaphragm was opened and the incision carried right down to the

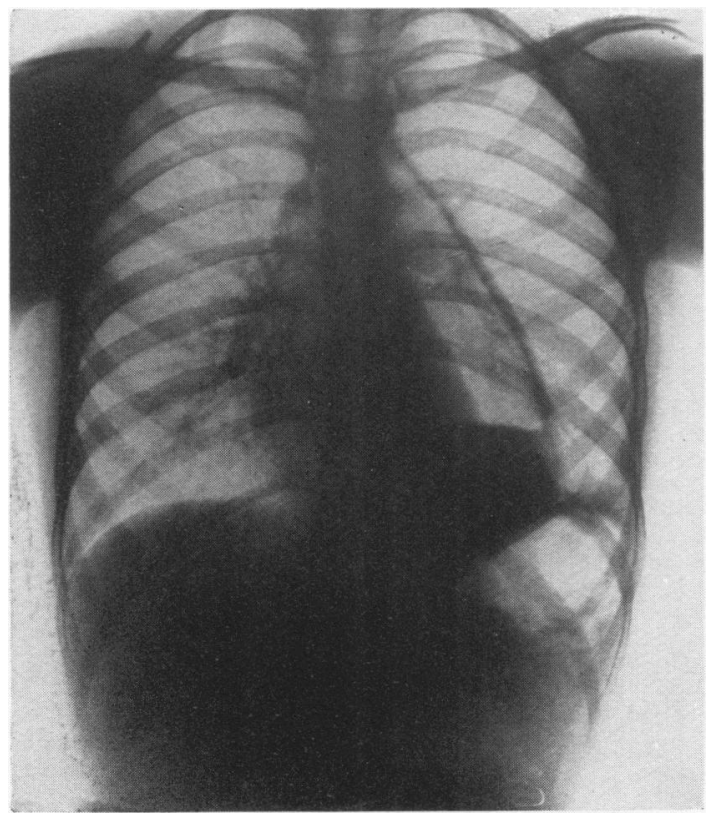

FIG. 7.-The oesophagus containing the stricture has been resected and the stomach anastomosed to the stump of the oesophagus above the arch of the aorta.

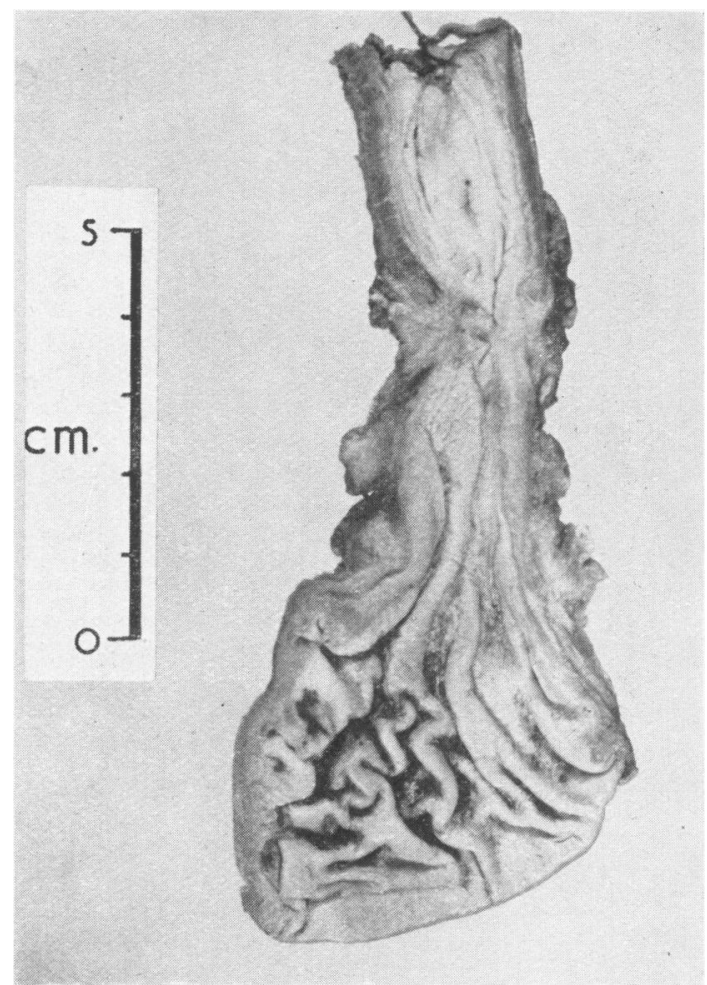

FIG. 8.-Operation specimen.

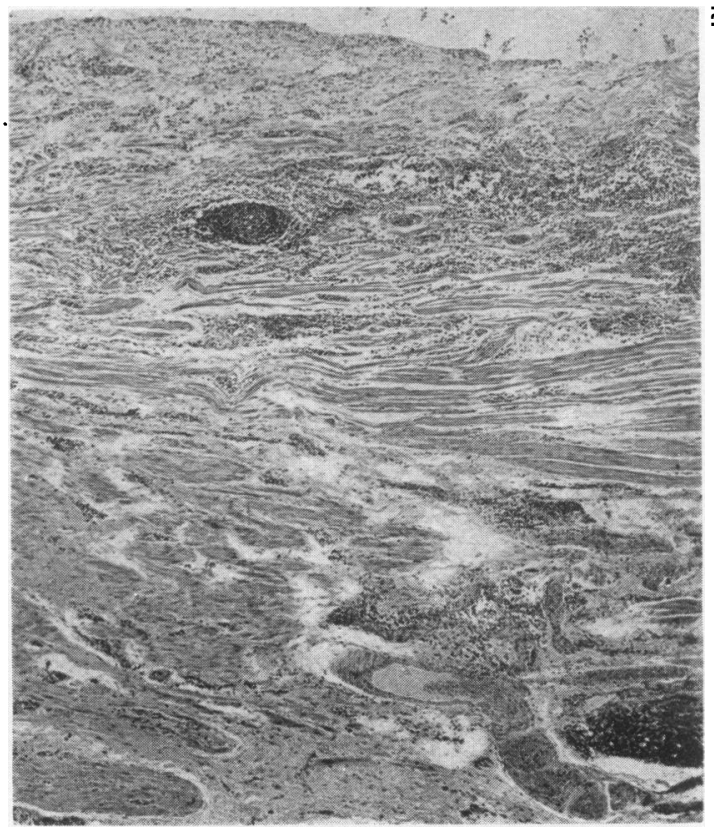

FIG. 9.-Histological appearance showing absence of epithelium of both cardia and oesophagus. 
oesophagus, dividing the right crus. The spleen was removed and the stomach was mobilized by ligaturing and dividing the gastro-colic omentum and the left gastric vessels. The mobilization was carried up to the lower half of the oesophagus. To obtain a good view of the oesophagus above the arch of the aorta, a second intercostal incision was made in the fourth interspace after drawing the scapula well forward. The oesophagus above the arch of the aorta was exposed by dividing the overlying pleura and the oesophagus itself was divided at the level of the arch of the aorta. The stomach was divided obliquely so that the line of section was from the fundus down to the middle of the lesser curvature. The cut end of the stomach was sutured and the fundus brought up in front of the arch of the aorta and anastomosed to the cut end of the oesophagus after having divided the pyloric sphincter without opening the lumen. An intercostal waterseal drainage tube was introduced and the rest of the incision closed.

Recovery was uninterrupted and symptoms vanished. At Christmas, 1952, the patient consumed a large dinner with ease (Fig. 7). At discharge on January 12, 1953, her weight was $62 \mathrm{lb}$. $(28 \cdot 1 \mathrm{~kg}$.).

By April 15, 1954, when she was admitted for excision of the tonsils and adenoids, the girl was asymptomatic nor was she keeping to an oesophagitis régime. Her weight was $65 \frac{1}{2} \mathrm{lb}$. $(29 \cdot 7 \mathrm{~kg}$.).

The specimen (Fig. 8) shows the site of the stricture. Histologically the epithelium, of both cardia and oesophagus at their junction, is either debased or absent. Where it is absent the lumen is lined with organized granulation tissue (Fig. 9).

\section{Summary}

Two patients are described in whom severe stricture formation occurred in the oesophagus, presumably the result of reflux oesophagitis. The process was not affected by any conservative attempts at control and resection had to be undertaken.

The histological appearance in Case 1 showed areas of osteoid tissue which seems an unusual finding in strictures of this nature.

Bibliography

Belsey, R. (1952). In Modern Trends in Gastro-enterology, Ch. 7, p. 128. Ed. Jones, F. A. London.

Kelly, A. B. (1930a). Proc. roy. Soc. Med., 23, 1521

(1930b). J. Laryng., 45, 680.

Sheldon, W. and Ogilvie, A. G. (1929). Archives of Disease in Childhood, 4, 347. 